\title{
PENGARUH CITRA PERUSAHAAN, KUALITAS LAYANAN DAN KEPUASAN NASABAH TERHADAP LOYALITAS PENGGUNAAN BNI MOBILE BANKING STUDI KASUS BNI KANTOR CABANG HARMONI
}

\author{
Kaledin Siadari \\ Program Studi Magister Manajemen Universitas Tarumanagara \\ mail.edinsiadari@gmail.com \\ Anas Lutfi \\ Program Studi Magister Manajemen Universitas Tarumanagara \\ Masuk : 01-06-2020, revisi : 26-06-2020 diterima untuk diterbitkan : 26-06-2020
}

\begin{abstract}
The purpose of this research is to find out the effect of corporate image, service quality, and customer satisfaction on the loyalty of BNI Mobile Banking use. The sampling technique used in this research is nonprobability sampling by accidental sampling using a quantitative approach by distributing questionnaires to 100 respondents. The data analysis method used in this research is multiple regression analysis. For operational variables using the Likert scale method of validity used a computer measuring instrument that is SPSS 26.0. The results showed that all independent variables have a simultaneous effect on the loyalty of BNI Mobile Banking usage positively and also have a positive effect on the loyalty of BNI Mobile Banking usage. Thus, corporate image, service quality, and customer satisfaction have positive affect and significance on the loyalty of BNI Mobile Banking usage, where the corporate image is the most dominant variable with a value of 0.342 .
\end{abstract}

Abstrak: Penelitian ini bertujuan untuk mengetahui pengaruh citra perusahaan, kualitas layanan dan kepuasan nasabah terhadap loyalitas penggunaan BNI Mobile Banking. Teknik pengambilan sampel menggunakan nonprobability sampling dengan cara accidental sampling, pendekatan kuantitatif dilakukan dengan cara menyebarkan kuesioner kepada 100 responden. Metode analisis data yang digunakan adalah analisis regeresi linear berganda, dan untuk operasional variabel menggunakan skala Likert dengan bantuan SPSS 26.0. Hasil penelitian menunjukkan bahwa semua variabel independen secara bersama-sama berpengaruh positif dan signifikan terhadap loyalitas penggunaan Mobile Banking dan juga berpengaruh positif dan signifikan secara individual terhadap loyalitas penggunaan Mobile Banking. Citra perusahaan merupakan variabel yang paling dominan dalam penelitian dengan nilai sebesar 0.342.

Keywords: Corporate Image, Service Quality, Customer Satisfaction, Loyalty, Mobile Banking

\section{PENDAHULUAN}

Era globalisasi dan teknologi informasi pada dewasa ini berkembang begitu cepat, perkembangan tersebut menyentuh seluruh sektor usaha barang dan jasa. Perusahaan dituntut untuk berpikir kreatif dan inovatif agar tetap dapat bersaing dan bertahan dalam persaingan usaha. Pembentukan citra perusahaan, kualitas layanan, kepuasan serta loyalitas konsumen yang tepat dapat menjadi cara efektif untuk memberikan dampak langsung terhadap peningkatan keunggulan bersaing suatu perusahaan terhadap perusahaan kompetitor. Citra perusahaan dapat didefinisikan sebagai kesan yang diperoleh sesuai dengan pengatahuan dan pengalaman sesorang tentang sesuatu hal. Zameer et al. (2015) berpendapat bahwa citra harus mencerminkan tujuan, nilai dan etika untuk menciptakan reputasinya dilingkungan yang kompetitif. Disamping itu, kualitas layanan juga menjadi penting karena akan berdampak langsung pada citra perusahaan tersebut. Kualitas layanan yang baik akan menggambarkan 
bagaimana citra perusahaan terliat baik atau buruk dimata konsumen dan masyarakat luas. Dengan terciptanya suatu citra dan kualitas layanan yang baik, maka akan memberikan suatu bentuk kepuasan tersendiri bagi konsumen, loyalitas terhadap produk barang dan jasa akan menciptakan suatu ikatan yang kuat antara konsumen dan perusahaan. Loyalitas dapat terbentuk apabila konsumen mendapatkan kesan yang baik terhadap citra perusahaan dan kepuasan terhadap kualitas layanan yang diterimanya dari perusahaan.

Tantangan usaha yang mengacu terhadap citra, kualitas layanan, kepuasan serta dampaknya terhadap loyalitas juga menyentuh sektor usaha perbankan. Menurut Tambunan (2011), bank merupakan lembaga keuangan mempunyai peranan yang sangat strategis dalam pembangunan suatu negara. Ditengah perkembangan teknologi informasi, transaksi perbankan telah berevolusi, nasabah tidak lagi menggunakan cara-cara tradisional dalam bertransaksi. Bank tidak lagi hanya dituntut untuk mengembangkan citra, kualitas layanan dan pembentukan kepuasan nasabah secara konvensional, namun Bank juga berkewajiban untuk melakukan terobosan terhadap perkembangan teknologi informasi dalam rangka menciptakan loyalitas nasabah kelolahan, serta untuk menarik nasabah baru. Pengembangan aplikasi Mobile Banking merupakan salah satu dari berbagai cara bagaimana Bank berinovasi menjawab tantangan perkembangan tersebut. Mobile banking telah didefinisikan dalam berbagai istilah, seperti $m$ banking (Sripalawatet al., 2011; Tran dan Corner, 2016); m-payment, $m$-transfer dan $m$-finance (Donner dan Tellez 2008); atau pocket banking (Amin et al. 2006). Terlepas dari itu semua, mobile banking pada umumnya didefinisikan sebagai aplikasi $m$-commerce, yang didukung oleh teknologi dan produk mobile untuk memungkinkan konsumen untuk memproses layanan perbankan pada perangkat mobile mereka sendiri, termasuk smartphone, tablet, jam tangan pintar dan produk teknologi pintar lainnya. Tujuan penelitian ini untuk mengetahui pengaruh citra perusahaan, kualitas layanan dan kepuasan nasabah terhadap penggunaan BNI Mobile Banking. Tujuan dari penelitian ini diharapkan dapat menjelaskan pengaruh citra perusahaan, kualitas layanan dan kepuasan nasabah terdapat penggunaan Mobile Banking kepada pihak perusahaan, dalam hal ini Bank BNI.

\section{TELAAH PUSTAKA \\ Mobile Banking}

Mobile Banking pertama sekali digunakan pada akhir tahun 1990-an oleh Deutsche Bank yang bekerja sama dengan perusahaan Jerman Paybox. Diawal kemunculannya, fasilitas ini hanya tersedia di negara-negara Eropa seperti Jerman, Spanyol, Swedia, Austria, dan Inggris. Setyawan (2018) menjelaskan bahwa Mobile Banking merupakan sebuah teknologi informasi berupa sebuah layanan aplikasi dari sebuah lembaga keuangan perbankan untuk membantu nasabah melakukan sejumlah transaksi keuangan yang dapat diakses langsung oleh nasabah melalui perangkat mobile seperti telepon pintar atau smartphone. Melalui perangkat smartphone, nasabah perbankan dapat mengakses layanan perbankan baik berupa transaksi keuangan maupun non-keuangan seperti manajemen rekening, informasi saldo, pemindahan, pembayaran tagihan, perubahan PIN dan lain sebagainya, tergantung bagaimana bank penyedia tersebut memfasilitasi layanan mobile banking yang mereka miliki (Riswandi, 2005).

\section{Citra Perusahaan}

Sutisna (2001) menyatakan bahwa citra adalah total persepsi terhadap suatu obyek yang dibentuk dengan memproses informasi dari berbagai sumber setiap waktu. Definisi citra menurut Renald Kasali (sebagaimana dikutip dari Iman, 2010) yaitu kesan yang timbul karena pemahaman akan suatu kenyataan. Dari pemahaman tersebut, dapat didefinisikan bahwa citra perusahaan sebagai kesan yang diperoleh sesuai dengan pengetahuan dan pengalaman seseorang terhadap sebuah perusahaan. Citra merupakan merupakan efek tunda bagi perusahaan, artinya citra yang dibentuk oleh perusahaan yang tidak berpengaruh secara langsung terhadap perusahaan, ini membutuhkan waktu yang relatif lama. 


\section{Kualitas Layanan}

Kotler (1997) meyatakan bahwa kualitas harus dimulai dari kebutuhan pelanggan dan berakhir pada persepsi pelanggan. Menurut Rehman et al. (2012), persepsi pelanggan mengenai kualitas layanan dapat dilihat setelah konsumen menggunakan produk atau memanfaatkan layanan dari sebuah perusahaan. Sehingga dapat dikatakan bahwa, kualitas layanan dapat diartikan sebagai tingkat kepuasan konsumen, sedangkan tingkat kepuasan konsumen itu sendiri didapatkan dari perbandingan atas jenis pelayanan yang nyata diterima oleh konsumen dengan jenis pelayanan yang diharapkan oleh konsumen.

\section{Kepuasan Nasabah}

Menurut Kotler et al. (2012), kepuasan merupakan fungsi dari kinerja yang dirasakan (perceived performance) dan harapan (expectations). Jika kinerja produk atau jasa lebih rendah dari harapan, konsumen akan merasa tidak puas. Jika kinerja sesuai harapan maka konsumen akan merasa puas, jika kinerja sampai melebihi harapan, maka konsumen akan merasa sangat puas (delighted). Kepuasan dapat didefinisikan sebagai perasaan senang atau kecewa seseorang dari membandingkan kinerja produk yang dirasakan dalam hubungan dan harapannya. Kepuasan adalah sebagai evaluasi setelah pembelian hasil dari perbandingan antara harapan sebelum pembelian dengan kinerja sesungguhnya.

\section{Loyalitas}

Hasan (2014) menjelaskan bahwa loyalitas merupakan kondisi psikologis yang berkaitan dengan sikap terhadap produk, konsumen akan membentuk keyakinan, menetapkan suka dan tidak suka, dan memutuskan apakah mereka ingin membeli produk. Untuk menggambarkan bahwa loyalitas tersebut tercipta dapat terlihat dari bagaimana sikap pelanggan melihat sebuah citra perusahaan, bagaimana mereka melakukan pembelian berulang, dan bagaiman usaha mereka menawarkan produk atau jasa tersebut ke orang lain (Wilkins et al., 2019).

Menurut Sugiyono (2005), hipotesis adalah jawaban sementara terhadap suatu rumusan masalah. Dikatakan sementara karena jawaban yang diberikan baru didasarkan pada teori yang relevan, belum didasarkan pada fakta-fakta empiris yang diperoleh melalui pengumpulan data dan analisis data. Berdasarkan pernyataan tersebut, maka dirumuskan bahwa hipotesis penelitian ini sebagai berikut:

H1 = Citra perusahaan mempengaruhi loyalitas penggunaan BNI Mobile Banking $\mathrm{H} 2$ = Kualitas layanan mempengaruhi loyalitas penggunaan BNI Mobile Banking H3 = Kepuasan nasabah mempengaruhi loyalitas penggunaan BNI Mobile Banking

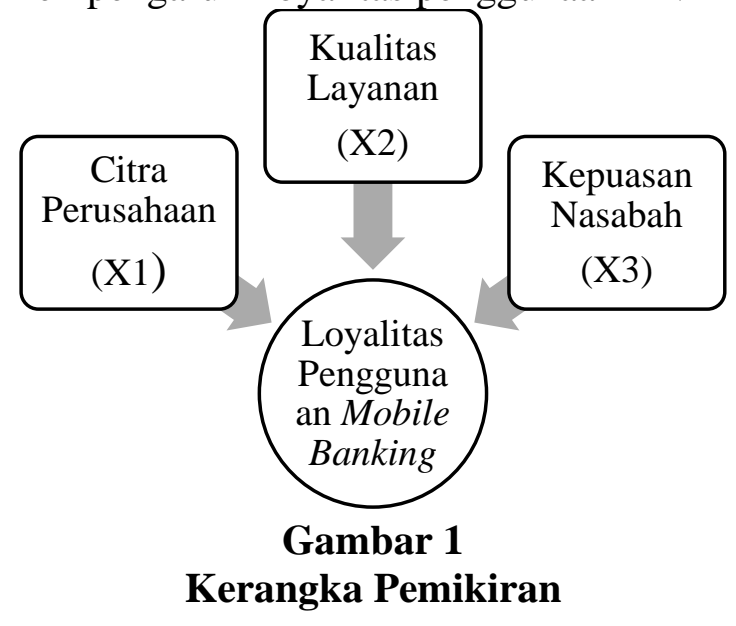

\section{METODOLOGI PENELITIAN}

Metode yang digunakan dalam penelitian ini adalah metode kuantitatif, yaitu pengukuran variabel-variabel penelitian dalam bentuk angka dan melakukan analisis dalam bentuk statistik. Populasi dalam penelitian ini adalah nasabah pengguna BNI Mobile Banking di Bank BNI Kantor Cabang Harmoni, dengan sampel penelitian adalah 100 responden. Metode pengambilan sampel menggunakan nonprobability sampling dengan accidental sampling. 
Berdasarkan data yang didapat, mayoritas karakteristik responden pada penelitian ini adalah wanita (52\%), berusia 21-30 tahun (55\%), pekerjaan pelajar atau mahasiswa (37\%), dengan lama penggunaan aplikasi BNI Mobile Banking $\geq 4$ tahun (45\%) dengan rata-rata penggunaan $\geq 15$ kali dalam sebulan $(70 \%)$.

Pada penelitian ini, variabel citra perusahaan, kualitas layanan dan kepuasan merupakan variabel independent, sedangkan loyalitas penggunaan merupakan variabel dependent. Dalam pengukuran variable, metode yang digunakan adalah Skala Likert dengan 5 (lima) pilihan; 1 menunjukan "sangat tidak setuju", 2 menunjukan tidak setuju", 3 menunjukan "netral", 4 menunjukkan "setuju' dan 5 menunjukan "sangat setuju". Metode analisa data menggunakan analisis regresi linear berganda. Sedangkan, untuk uji asumsi seperti uji normalitas, uji multikolinieritas dan uji heteroskedastisitas telah dilakukan sebelumnya dan hasilnya menunjukan semua uji asumsi sudah terpenuhi. Pengujian dalam penelitian ini menggunakan program SPSS 26.0. Taraf signifikansi yang digunakan dalam penelitian ini adalah 0,05.

\section{Tabel 1}

Variabel dan Pengukuran

\begin{tabular}{lll}
\hline Variabel & Jumlah Item & Sumber \\
\hline Independent Variable & & \\
1. Citra Perusahaan & 4 & Harrison (2005) \\
2. Kualitas Layanan & 5 & Wu et al. (2012); Molapo (2018) \\
$\begin{array}{l}\text { 3. Kepuasan } \\
\begin{array}{l}\text { Dependent Variable } \\
\text { 1. Loyalitas Penggunaan }\end{array}\end{array}$ & 5 & Tjiptono (2000) \\
\hline
\end{tabular}

\section{ANALISA DAN PEMBAHASAN}

Berdasarkan hasil pengujian hipotesis maka dapat disimpulkan bahwa variabel citra perusahaan, kualitas layanan dan kepuasan secara simultan berpengaruh positif dan signifikan terhadap loyalitas penggunaan fasilitas BNI Mobile Banking. Ini berarti nasabah memiliki loyalitas yang tinggi terhadap penggunaan BNI Mobile Banking karena adanya citra perusahaan, kualitas layanan dan kepuasan nasabah yang baik. Hipotesis H1 sesuai dengan penelitian Purba (2015) yang mengemukakan bahwa citra perusahaan menunjukkan hasil yang positif dan signifikan terhadap loyalitas pelanggan. Jika citra perusahaan dikelola dengan baik akan menghasilkan efek yang positif dengan meningkatkan pengetahuan tentang aspek perilaku pelanggan dalam pembuatan keputusan. Selanjutnya Hipotesis H2 sesuai dengan Nursiana (2011) yang menemukan bahwa kualitas layanan secara positif dan signifikan mempengaruhi loyalitas nasabah. Ini menunjukkan bahwa semakin nyata kualitas layanan yang dirasakan nasabah maka makin meningkat juga loyalitas nasabah tersebut. Kemudian untuk hipotesis H3 juga sesuai dengan Magdalena (2018) yang mengatakan bahwa kepuasan berpengaruh positif dan signifikan terhadap loyalitas. Jika faktor-faktor yang mempengaruhi kepuasan nasabah diperhatikan maka akan dapat meningkatkan loyalitas nasabah dari Bank yang bersangkutan. Selanjutnya untuk menunjukan hasil dari pengujian hipotesis dari penelitian ini dapat diliat pada tabel 2.

Dengan demikian maka seluruh hipotesis penelitian ini terbukti dengan adanya data secara empiris. Loyalitas penggunaan mobile banking dapat diprediksi oleh citra perusahaan, kualitas layanan dan kepuasan nasabah. Dengan demikian, maka dapat dilihat bahwa loyalitas penggunaan mobile banking dapat dipengaruhi oleh citra Bank BNI sebagai Bank BUMN, citra perusahaan yang baik, memiliki tanggung jawab sosial yang besar mempengaruhi keputusan nasabah dalam menggunakan produk jasa perbankan. Begitu juga dengan kualitas layanan yang dirasakan, mesti dalam penelitian menunjukkan angka yang paling kecil diantara ketiga variabel, namun kualitas layanan dari BNI Mobile Banking dirasa baik, aplikasi memiliki banyak fitur yang dapat membantu transaksi perbankan nasabah. Dalam hal kepuasan, nasabah dikategorikan puas, ini dibuktikan dilapangan bahwa jarangnya terjadi keluhan atas aplikasi. 


\begin{tabular}{|c|c|c|c|c|c|c|}
\hline \multicolumn{7}{|c|}{$\begin{array}{l}\text { Tabel } \\
\text { Iasil Koefisie }\end{array}$} \\
\hline \multirow[b]{2}{*}{ Model } & & \multirow{3}{*}{$\begin{array}{l}\text { Unst: } \\
\text { B } \\
791\end{array}$} & ed Coefficients & \multirow{2}{*}{$\begin{array}{l}\text { Standardized } \\
\text { Coefficients } \\
\text { Beta }\end{array}$} & \multirow[b]{2}{*}{$\mathrm{t}$} & \multirow[b]{2}{*}{ Sig. } \\
\hline & & & Std. Error & & & \\
\hline 1 & (Constant) & & 1.018 & & .777 & .439 \\
\hline & Citra Perusahaan (X1) & .342 & .081 & .359 & 4.212 & .000 \\
\hline & Kualitas Layanan (X2) & 242 & .084 & .283 & 2.889 & .005 \\
\hline & Kepuasan (X3) & .254 & .080 & .292 & 3.167 & .002 \\
\hline
\end{tabular}

a. Dependent Variable: Loyalitas Nasabah (Y)

\section{KESIMPULAN DAN SARAN Kesimpulan}

Penelitian ini memperoleh hasil bahwa variabel citra perusahaan, kualitas layanan dan kepuasan secara simultan berpengaruh positif dan signifikan terhadap loyalitas penggunaan fasilitas BNI Mobile Banking. Variabel citra perusahaan, kualitas layanan dan kepuasan juga secara parsial berpengaruh positif dan signifikan terhadap loyalitas penggunaan fasilitas BNI Mobile Banking. Dari ketiga variabel bebas dalam penelitian ini, variabel citra perusahaan merupakan variabel yang paling dominan berpengaruh signifikan terhadap loyalitas penggunaan Mobile Banking, dilihat dari nilai standardized coefficients beta yaitu sebesar 0,342 .

\section{Saran}

Dalam penelitian ini tanggapan responden terhadap citra perusahaan merupakan kategori yang paling tinggi yang mempengaruhi loyalitas penggunaan BNI Mobile Banking dibandingkan dengan variable lain, maka daripada itu disarankan Bank BNI KC Harmoni hendaknya selalu menjaga citra baik tersebut dimata masyarakat luas, khususnya dimata nasabah. Bank BNI juga disarankan untuk terus berupaya berinovasi dalam mengembangkan kualitas layanan untuk meningkatkan kepuasan nasabah agar loyalitas pengguna BNI Mobile Banking semakin meningkat. Dalam hal kualitas layanan, variabel ini mendapat nilai paling rendah dari ketiga variabel yang mempengaruhi loyalitas penggunaan BNI Mobile Banking.

\section{DAFTAR PUSTAKA}

Amin, H., Hamid, M.R.A., Tanakinjal, G.H. \& Lada, S. (2006). Undergraduate attitudes and expectations for mobile banking. Journal of Internet Banking and Commerce, 11(3), 2006-2012.

Donner, J. \& Tellez, C.A. (2008). Mobile banking and economic development: linking adoption, impact, and use. Asian Journal of Communication, 18(4), 318-332.

Griffin, J. (2007). Customer Loyalty (Edisi Revisi dan Terbaru). Jakarta: Erlangga.

Harrison, S. (2005). Public Relations: An Introduction. New York: Thomson Learning.

Hasan, A. (2014). Marketing dan Kasus-kasus Pilihan (Cetakan Kedua). Yogyakarta: CAPS (Center for Academic Publishing Service).

Iman, M. (2010). Citra Perusahaan Seri Manajemen Pemasaran. Jakarta: Gramedia.

Kotler, P., \& Keller, K., L. (2012). Manajemen Pemasaran (Jilid 1, Ed. 12). Jakarta: PT Indeks. Magdalena, M. (2018). Pengaruh kepuasan nasabah terhadap loyalitas nasabah KPR BTN pada PT. Bank Tabungan Negara Tbk. cabang Padang. Jurnal IPTEK Terapan, 2(2).

Nursiana, A. (2011). Pengaruh Kualitas layanan terhadap loyalitas nasabah dengan intermediasi kepuasan nasabah dan nilai yang dirasakan nasabah. Ultima Management: Jurnal Ilmu Manajemen, 3(1), 1-15.

Purba, Roy P., \& Ibrahim, M. Pengaruh citra perusahaan terhadap loyalitas pelanggan (Studi kasus PT. Bintang Utara Perwakilan Dolok Sanggul). Jurnal Online Mahasiswa Fakultas Ilmu Sosial dan Ilmu Politik Universitas Riau, 4(1), 1-13. 
Rehman, M., \& Afsar, B. (2012). Relationship among corporate image, intangible perceived quality, choosing, habit and customer loyalty. Journal Management \& Marketing, 10(1).

Riswandi, B. (2005). Aspek Hukum Internet Banking. Jakarta: Raja Grafindo Persada.

Setyawan, O.E. (2018). Pengaruh Kualitas Pelayanan, Reputasi Perusahaan, dan Kepuasan

Nasabah pada Penggunaan Mobile Banking di PT Bank Sinar Mas. Jakarta: Universitas Tarumanagara.

Sripalawat, J., Thongmak, M. \& Ngramyarn, A. (2011). M-banking in metropolitan Bangkok and acomparison with other countries. Journal of Computer Information Systems, 51(3), 67-76.

Sutisna. (2001). Perilaku Konsumen dan Komunikasi Pemasaran. Bandung: PT Remaja Rosdakarya.

Tambunan, T. (2011). Krisis Ekonomi Indonesia: Teori dan Empiris. Jakarta: Penerbit Universitas Trisakti.

Tjiptono, F. (2007). Strategi Pemasaran. Yogyakarta: Penerbit Andi.

Tran, H.T.T. and Corner, J. (2016). The impact of communication channels on mobile banking adoption. International Journal of Bank Marketing, 34(1), 78-109.

Wilkins, H., Merrilees, B., Herington, C. (2009). The determinants of loyalty in hotels. Journal of Hospitality Marketing \& Management, 19, 1-21.

Wu, Y.L., Tao, Y.H., \& Yang, P.C. (2012). Learning from the past and present: measuring internet banking service quality. Service Industry Journal, 32(2).

Zameer, H., Tara, A., Kausar, U., \& Mohsin, A. (2015). Impact of service quality, corporate image and customer satisfaction towards customers' perceived value in the banking sector in Pakistan. International Journal of Bank Marketing, 33(4), 442-456. 